\title{
SOSIABILITAS POLA RUANG DI KAWASAN GUA MARIA
}

\author{
Angelique Milleanda \\ Mahasiswa Prodi Arsitektur, Fak. Teknik Sipil dan Perencanaan, Universitas Trisakti \\ e-mail: angelique05217015@std.trisakti.ac.id \\ Maria Immaculata Ririk Winandari \\ Dosen Prodi Arsitektur, Fak. Teknik Sipil dan Perencanaan,Universitas Trisakti \\ e-mail:mi.ririk@trisakti.ac.id \\ Julindiani Iskandar \\ Dosen Prodi Arsitektur, Fak. Teknik Sipil dan Perencanaan, Universitas Trisakti \\ e-mail: yulindiani@trisakti.ac.id
}

\begin{abstract}
ABSTRAK
Sosiabilitas ruang di Gua Maria dikatakan tercapai jika pengunjung dapat merasakan kedekatan antar sesama manusia sekaligus keterikatan dengan Sang Maha Pencipta. Umumnya penyusunan kawasan gua Maria selalu terdapat ruang terbuka yang menjadi penghubung antara kawasan ibadah dan ruang publik. Kemudian alam menjadi komponen untuk membentuk pola ruang sakral. Oleh karena itu penelitian ini bertujuan untuk mengetahui sosiabilitas pola ruang yang diterapkan pada kawasan gua Maria. Langkah-langkah agar mendapatkan suatu pola ruang maka dilakukan dengan cara mengidentifikasi dan menganalisis lima strategi dalam menciptakan ruang publik yang bagus. Kemudian menggunakan studi kasus kawasan gua Maria antara lain kawasan gua maria Lourdes di Perancis, kawasan gua Maria Pohsarang di Kediri, dan kawasan gua Maria Sendangsono di Yogyakarta. Hasil penelitian menunjukan dalam strategi atraksi dan destinasi (Attractions \& Destinations), suatu ruang memberi kesan pertama yang positif dan membuat kesan menarik. Dalam strategi identitas dan tampilan (Identity \& Image) terdapat lima variabel yaitu paths, edges, districts, nodes, dan landmark. Dalam strategi fasilitas (Amenities) bisa berupa taman, jalur pejalan kaki, toilet,parkir, dan tempat duduk. Dalam strategi penggunaan di waktu yang berbeda (Uses at Different Times) diklasifikasi menjadi tiga variabel berdasarkan penggunaan yaitu sepanjang hari, penggunaan malam hari, dan penggunaan tahunan.
\end{abstract}

Kata kunci : Penataan ruang, Sosiabilitas, Kawasan Gua Maria,

PAWON: Jurnal Arsitektur, Nomor 01 Volume VI, Januari - Juni Tahun 2022, ISSN 2597-7636 


\begin{abstract}
The sociability of space in the Maria Cave is said to be achieved if visitors can feel the closeness between fellow humans as well as an attachment to the Almighty Creator. Generally, the arrangement of the Maria cave area always has an open space that is a liaison between the worship area and public space. Then nature becomes a component to form a pattern of sacred space. Therefore, this study aims to determine the sociability of the spatial pattern applied to the Maria cave area. The steps to obtain a spatial pattern are carried out by identifying and analyzing five strategies in creating a good public space. Then using case studies of the Maria cave area, including the Maria Lourdes cave area in France, the Maria Pohsarang cave area in Kediri, and the Maria Sendangsono cave area in Yogyakarta. The results show that in the strategy of attractions and destinations (Attractions \& Destinations), a space gives a positive first impression and makes an interesting impression. In the identity and display strategy (Identity \& Image) there are five variables, namely paths, edges, districts, nodes, and landmarks. In the facilities strategy (amenities) it can be in the form of parks, pedestrian paths, toilets, parking, and seats. In the strategy of using at different times (Uses at Different Times) it is classified into three variables based on usage, namely throughout the day, night use, and annual use.
\end{abstract}

\title{
Keywords : Spatial planning, Sociability, Maria Cave
}

\section{PENDAHULUAN}

Pembahasan mengenai sosiabilitas di kawasan sakral sangat menarik karena ada kontradiksi antara kegiatan privat dan publik. Penelitian kawasan sakral dan kegiatan publik telah dilakukan oleh peneliti terdahulu. Chogle (2017) mengungkapkan adanya hubungan antara ruang religius dengan ruang publik serta. Community Design Collaborative (2019) mengeksplorasi tempat-tempat suci yang mendukung keterlibatan sipil, kohesi sosial, dan ekuitas lingkungan. Penelitian tersebut membahas mengenai tempat-tempat suci di ruang publik yang dapat beradaptasi dengan lingkungan sekitar. Penelitian dengan fokus sosiabilitas pola ruang di kawasan gua Maria belum pernah dilakukan sebelumnya.

Lingkungan yang ramah bertujuan untuk mendorong interaksi kolektif (Hall,1982). Proses sosialisasi sangat penting dengan membangun

PAWON: Jurnal Arsitektur, Nomor 01 Volume VI, Januari - Juni Tahun 2022, ISSN 2597-7636 
komunikasi. Terutama di tempat-tempat sakral seperti Gua Maria yang digunakan sebagai wisata rohani. Keterkaitan antara pariwisata dengan ziarah ke tempat-tempat suci keagamaan. Setelah melakukan banyak aktivitas dan seseorang mulai merasa lelah ia mencari ketenangan batin dengan melakukan kegiatan yang berhubungan dengan spiritual. Oleh karena itu merupakan peran yang besar karena mencari cara agar seseorang dapat melekatkan diri antara satu sama lain maupun untuk spiritual (Kinney,2013). Tempat-tempat suci memiliki potensi untuk menghasilkan pengalaman individu yang kuat dan rasa kebersamaan yang besar dari pertimbangan desain dan fasilitas tempat suci.

Penciptaan dan identifikasi tempat-tempat suci diawali dengan pembagian yang jelas antara ruang sakral dan profan. Sakral sebagai tempat keagamaan atau spiritual dan profan adalah area biasa dan seharihari (Eliade,1961). Ruang sosial dibuat untuk mempertegas pengalaman individu akan tempat ibadah dan ruang publik untuk berkumpul. Kedua tempat ini dapat terhubung dengan adanya ruang terbuka yang memiliki aktivitas religius (Chogle,2017). Penelitian ini mengeksplorasi sosiabilitas pola ruang di kawasan Gua Maria melalui indentifikasi dan analisis kehidupan di ruang publik (street life) (Project for Public Spaces,2007).

\section{TINJAUAN PUSTAKA}

Ruang publik adalah ruang dimana masyarakat umum memiliki akses dan menjadi pengatur kehidupan ruang publik. Merujuk Project for Public Space (2014), kehidupan di ruang publik dapat ditinjau berdasar empat strategi penciptaan ruang. Keempat strategi tersebut yaitu, atraksi dan destinasi, identitas dan tampilan, fasilitas, dan Penggunaan di waktu yang berbeda.

\subsection{Atraksi dan destinasi}

Ruang publik sangat penting untuk kesejahteraan semua orang. Mereka memberi kesempatan untuk relaksasi, rekreasi dan bersosialisasi. Ruang publik yang aktif, aman dan menyenangkan membuat orang tertarik (Victoria State Government, 2016). Faktor-faktor yang dapat menarik pengunjung adalah membuat kesan pertama yang positif, hubungan emosional sensual pengunjung, interaksi yang berkesan dan menarik, fungsionalitas, dan berkelanjutan (Steven, 2017). Dalam merencanakan penting juga untuk

PAWON: Jurnal Arsitektur, Nomor 01 Volume VI, Januari - Juni Tahun 2022, ISSN 2597-7636 
mempertimbangkan kegiatan untuk pria dan wanita, orang-orang dari berbagai usia, dan juga penggunaan pada waktu yang berbeda-beda (Project for Public Spaces, 2014).

\subsection{Identitas dan tampilan}

Menciptakan citra positif membutuhkan tempat yang nyaman dan terpelihara dengan baik, serta menumbuhkan rasa kepemilikan yang kuat. Hester, 1984 menyimpulkan faktor sosial dengan "ruang yang nyaman" mengacu pada kenyamanan psikologis. Ruang yang memungkinkan pengguna untuk menyeimbangkan keteraturan dan keragaman. Untuk mengidentifikasi tampilan ruang publik terdapat lima cara yaitu, paths, edges, districts, nodes, dan landmark (Lynch, 1960). Paths, membuat jalur ruang yang berkesan disetiap langkahnya. Ini membantu orang mengorientasikan diri dan memberikan pengalaman yang tak terlupakan. Edges, merupakan elemen pengikat ruang atau menciptakan batasan ruang. Menciptakan batasan ruang dapat menciptakan perasaan yang berbeda di setiap area. Edges dibedakan oleh material atau karakter. Districts, membuat area dengan karakter yang berbeda di dalam ruang untuk membuat ruang lebih mudah dikenali dan menarik bagi pengguna. Nodes, membuat berbagai tujuan atau aktivitas didalam ruang agar orang memiliki alasan pergi ke ruang publik tersebut. Landmark, merancang atau menempatkan sesuatu elemen simbolis yang berkaitan dengan sejarah, budaya, atau pengguna ruang. Landmark bisa menjadi pusat perhaian dan membentuk hubungan yang kuat antara kota dan ruang publik (Dougherty, 2006).

\subsection{Fasilitas}

Fasilitas menjadi salah satu aspek desain yang menjamin pengunjung untuk melakukan aktivitas lebih mudah dan nyaman. Hasil penelitian Nasution (2016) menunjukan bahwa fasilitas yang tersedia di ruang publik adalah taman, jalur pejalan kaki, toilet, area parkir, tempat duduk dan taman bermain anak. Hampir setiap tempat duduk diatur menghadap tempat tertentu. Sementara orang-orang duduk mereka dapat menikmati pemandangan alam yang indah, yang memberikan mereka untuk bersantai (Zhuang, 2008).

\subsection{Penggunaan di waktu yang berbeda}

Terdapat 3 (tiga) waktu penggunaan yang berbeda yaitu sepanjang hari, malam hari, dan tahunan. Penggunaan sepanjang hari terdapat tiga jenis

PAWON: Jurnal Arsitektur, Nomor 01 Volume VI, Januari - Juni Tahun 2022, ISSN 2597-7636 
penggunaan ruang publik yaitu, aktivitas yang diperlukan, aktivitas opsional, dan aktivitas sosial (Gehl 1987). Aktivitas yang diperlukan seperti pergi bekerja dan menjalankan tugas, aktivitas opsional terjadi ketika orang tersebut ingin melakukannya. Contoh duduk dibangku taman atau berjalanjalan. Aktivitas opsional secara langsung dipengaruhi oleh lingkungan fisik seseorang. Lingkungan yang menyenangkan mendorong penggunaan opsional. Aktivitas sosial terjadi karena adanya lawan bicara atau terlibat dalam beberapa aktivitas dengan orang lain (Dougherty, 2006). Penggunaan malam hari dengan menggunakan cahaya dan seni cahaya yang inovatif dapat membantu meningkatkan penggunaan dan vitalitas di ruang publik (Dougherty, 2006). Penggunaan tahunan memanfaatkan acara tahunan seperti bazar, parade, dan aktivitas rekreasi untuk mengaktifkan ruang sepanjang tahun (Project for Public Spaces, 2014).

\section{METODE PENELITIAN}

Metode penelitian menggunakan data sekunder yang didapatkan melalui studi literatur. Studi literatur dilakukan dengan pencarian data, mengumpulkan data, analisa dan menyimpulkan data dari kumpulan kasus. Pengumpulan data untuk penelitian ini berkaitan dengan pembahasan teori sosiabilitas dan kawasan gua Maria. Sosiabilitas merujuk mengenai kehidupan di ruang publik. Kemudian teori tersebut digunakan untuk menganalisis data studi sosiabilitas pola ruang di kawasan gua Maria. Studi kasus kawasan gua Maria yang akan diteliti adalah kawasan gua Maria Lourdes, kawasan gua maria Sendangsono dan kawasan gua Maria Pohsarang. Studi kasus ini akan dijabarkan menggunakan tabel perbandingan dan hasil perbandingan ini menemukan temuan baru yang dapat diterapkan pada pola ruang kawasan gua Maria.

\section{HASIL DAN PEMBAHASAN}

Terdapat tiga kasus kawasan gua Maria yang akan digunakan untuk dikaji berdasarkan elemen sosiabilitas untuk menentukan sosiabilitas pola ruang pada kawasan gua Maria. Elemen tersebut adalah kehidupan di ruang publik (street life). Dalam elemen ini mengindetifikasi empat strategi dalam menciptakan ruang yaitu atraksi dan destinasi, identitas dan tampilan, fasilitas, dan Penggunaan di waktu yang berbeda (Project for Public Space,

PAWON: Jurnal Arsitektur, Nomor 01 Volume VI, Januari - Juni Tahun 2022, ISSN 2597-7636 
2014). Indetifikasi ini digunakan untuk menganalisis tiga kasus kawasan gua Maria.

\subsection{Atraksi dan destinasi (Attractions \& Destinations)}

Pada ketiga kasus memiliki tujuan yang sama yaitu berziarah rohani. Kegiatan yang ada pada ketiga kasus juga kurang lebih sama berdevosi kepada Bunda Maria, dan berdoa. Tetapi ketiga kasus ini memiliki cerita yang berbeda dan membuat orang-orang tertarik untuk mengujungi tempat tersebut. Pada kasus pertama dikenal karena cerita bahwa Perawan Maria menampakkan diri kepada Marie Bernadette Soubirous (Peyremale Ps.) dan mata air yang diyakini dapat menyembuhkan. Sedangkan pada kasus kedua dikenal karena sumber air Sendangsono. Kasus ketiga dikenal karena terinspirasi dari Gua Maria Lourdes di Perancis. Masing-masing kasus dapat membuat kesan pertama yang positif kepada orang-orang. Hal ini memperkuat pertanyaan oleh (Steven, 2017) tentang faktor-faktor yang dapat menarik pengunjung.

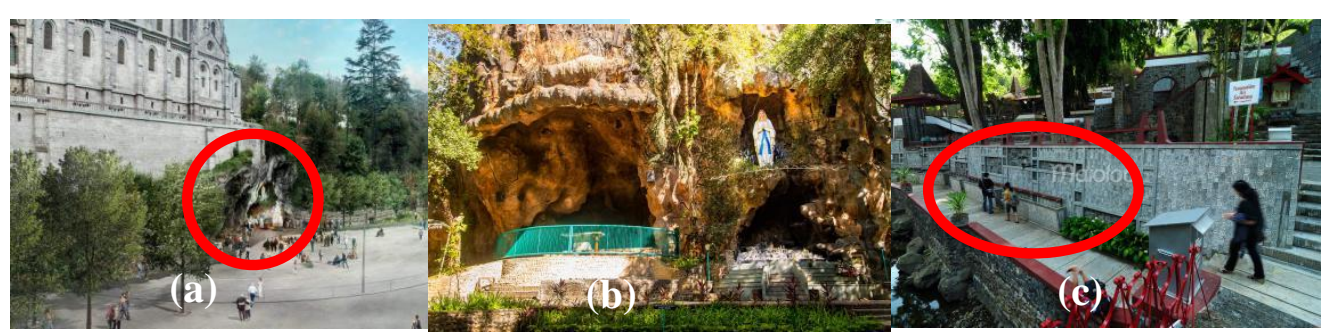

Sumber: Nazarettour.com
Sumber: adira.co.id

Gambar. 1

(a) Tempat Perawan Maria menunjukan diri di Gua Maria Lourdes, Perancis (b) Gua Maria Pohsarang, Kediri (c) Sumber air Sendangsono di kawasan Gua Maria Sendangsono, Yogyakarta

\subsection{Identitas dan tampilan (Identity \& Image)}

Berdasarkan identifikasi tampilan ruang yaitu paths, edges, districts, nodes, dan landmark (Lynch, 1960). Pada kasus pertama paths dibuat dengan dengan pola ruang hierarki. Pola hierarki dengan meletakkan Gereja ditengah dan berukuran paling besar sehingga orang-orang yang

PAWON: Jurnal Arsitektur, Nomor 01 Volume VI, Januari - Juni Tahun 2022, ISSN 2597-7636 
berkunjung mata akan langsung tertuju pada Gereja. Untuk kasus dua dan tiga disusun sevara simetri yang menciptakan keterhubungan gerak antar bangunan dan manusia serta juga memberikan visual disepanjang lintasan.

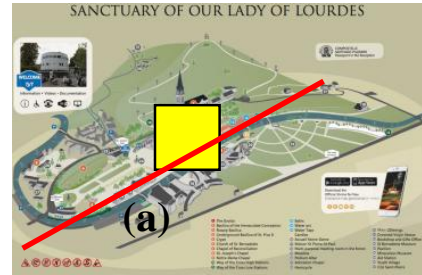

Sumber: Piets-art.com

Sumber: JohanSurya.id Gambar. 2

(b)
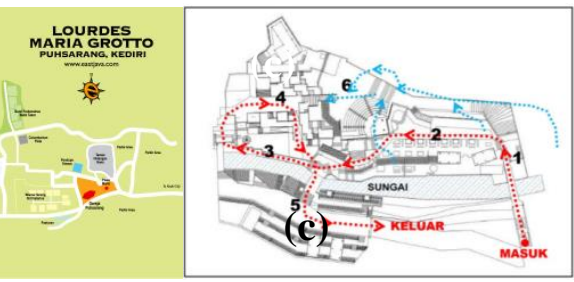

Sumber: tuguwisata.com

(a) Pola Ruang Hierarki pada Gereja Lourdes, Perancis (b) Pola Ruang Simetri di kawasan Gua Maria Pohsarang, Kediri (c) Pola Ruang Simetri di kawasan Gua Maria Sendangsono, Yogyakarta

Selanjutnya Edges pada kasus pertama dan ketiga tanaman adalah pemisah ruang atau batasan ruang sedangkan kasus kedua alur sungai yang menjadi batasan ruang. Districts, pada ketiga kasus tidak memiliki ruang yang berbeda. Perbedaan terlihat lebih jelas kepada bentuk bangunan. Nodes, ketiga kasus orang-orang yang datang rata-rata memiliki tujuan yang sama yaitu berdevosi kepada Bunda Maria di Gua Maria. Landmark, dikasus pertama terdapat di Gereja, dan untuk kasus dua dan tiga pada Gua Maria. Lima cara identifikasi identitas dan tampilan pada suatu ruang publik memperkuat pernyataan (Dougherty, 2006).

\subsection{Fasilitas (Amenities)}

Ketiga kasus memiliki fasilitas yang lengkap sehingga pengunjung melakukan aktivitas lebih mudah dan nyaman. Ini memperkuat pernyataan (Nasution, 2016) bahwa fasilitas yang tersedia adalah taman, jalur pejalan kaki, toilet, area parkir, dan tempat duduk.

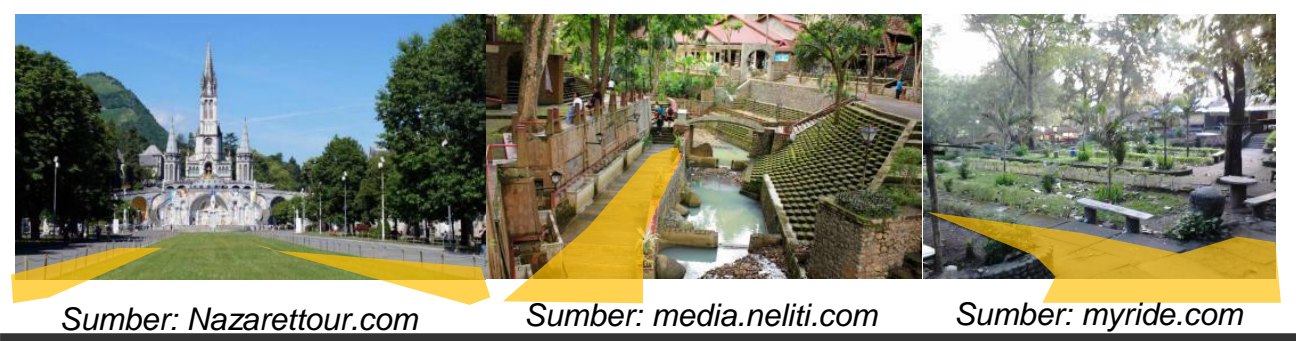

PAWON: Jurnal Arsitektur, Nomor 01 Volume VI, Januari - Juni Tahun 2022, ISSN 2597-7636 
Gambar. 3

(a) Jalur Pejalan Kaki Kawasan Gua Maria Lourdes, Perancis (b) Jalur Pejalan Kaki Kawasan Gua Maria Pohsarang, Kediri (c) Jalur Pejalan Kaki Kawasan Gua Maria Sendangsono, Yogyakarta

\subsection{Penggunaan di waktu yang berbeda (Uses at Different Times)}

Penggunaan sepanjang hari diketiga kasus ini adalah aktivitas yang sama yaitu untuk ziarah rohani, berdevosi kepada Bunda Maria, dan berdoa. Selesai berdoa atau sebelum orang-orang berkeliling menikmati fasilitas dan keindahan kawasan, atau duduk bersantai sambil berbicara. Hal ini memperkuat pernyataan (Gehl, 1987) tentang tiga jenis penggunaan ruang publik. Penggunaan malam hari Ketiga kasus memiliki kegiatan yang berbeda-beda pada kasus pertama kegiatan utama pada malam hari adalah prosesi obor Maria, kasus kedua berdoa di depan Gua Maria, dan kasus ketiga Trikatan Jumat Legi. Mayoritas kegiatan ini menggunakan lilin dan lampu hanya digunakan sedikit saja sebagai penerangan di bangunan dan jalur pedestrian. Sehingga penggunaan cahaya lilin dan lampu ini dapat memperkuat pernyataan (Dougherty, 2006) tentang penggunaaan malam hari.

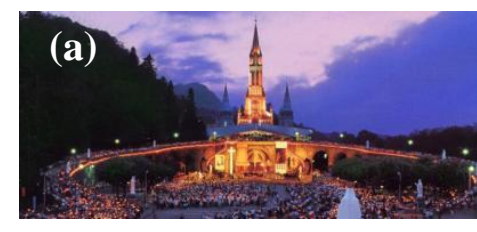

Sumber: Nazarettour.com

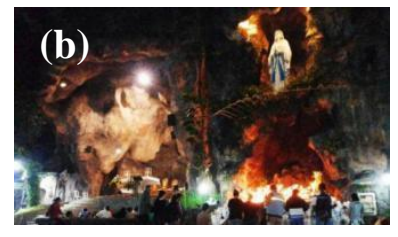

Sumber: Jejakpiknik.com

Gambar. 4

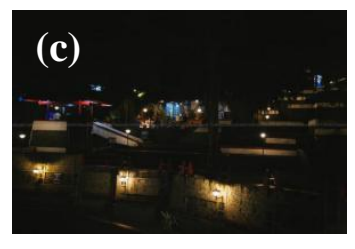

Sumber: Jatimtimes.com

(a) Prosesi Obor Maria di Kawasan Gua Maria Lourdes, Perancis (b) Trikatan Jumat Legi Kawasan Gua Maria Pohsarang, Kediri (c) Trikatan Jumat Legi Kawasan Gua Maria

Penggunaan tahunan pada agama Katolik yang biasa disebut tahun Liturgi terdapat beberapa hari-hari peringatan dan hari besar tersebut dirayakan. Hari-hari yang dirayakan setiap tahunnya adalah natal, jumat agung, paskah, kenaikan Yesus Kristus, Rabu Abu, Rosario, dan lainnya. Adanya beberapa acara yang dirayakan tahunan memperkuat pernyataan (Project for Public Spaces, 2014) tentang mengaktifkan ruang sepanjang tahun.

PAWON: Jurnal Arsitektur, Nomor 01 Volume VI, Januari - Juni Tahun 2022, ISSN 2597-7636 
Tabel 1.

\section{Kesimpulan Kasus}

\begin{tabular}{|c|c|c|c|c|c|}
\hline \multicolumn{2}{|c|}{ Unsur } & $\begin{array}{c}\text { Sanctuary of } \\
\text { Our Lady of } \\
\text { Lourdes, } \\
\text { Perancis }\end{array}$ & $\begin{array}{c}\text { Gua Maria } \\
\text { Sendangsono, } \\
\text { Yogyakarta }\end{array}$ & $\begin{array}{l}\text { Gua Maria } \\
\text { Pohsarang, } \\
\text { Kediri }\end{array}$ & Temuan \\
\hline \multicolumn{2}{|c|}{$\begin{array}{c}\text { Atraksi dan destinasi } \\
\text { (Attractions \& } \\
\text { Destinations) }\end{array}$} & $\begin{array}{l}\text { Perawan Maria } \\
\text { menampakan } \\
\text { diri kepada } \\
\text { Marie } \\
\text { Bernadette dan } \\
\text { mata air yang } \\
\text { diyakini dapat } \\
\text { menyembuhkan }\end{array}$ & $\begin{array}{l}\text { Sumber air } \\
\text { Sendangsono }\end{array}$ & $\begin{array}{l}\text { Terinspirasi dari } \\
\text { Gua Maria } \\
\text { Lourdes di } \\
\text { Perancis. }\end{array}$ & $\begin{array}{l}\text { Kesan } \\
\text { pertama yang } \\
\text { positif } \\
\text { membuat } \\
\text { kesan } \\
\text { menarik }\end{array}$ \\
\hline \multirow[t]{4}{*}{$\begin{array}{c}\text { Identita } \\
\text { s dan } \\
\text { tampila } \\
\mathrm{n} \\
\text { (Identit } \\
y \& \\
\text { Image) }\end{array}$} & Paths & Hierarki & Simetri & Simetri & $\begin{array}{l}\text { Membentuk } \\
\text { pola ruang } \\
\text { yang } \\
\text { berkesan } \\
\text { disetiap } \\
\text { langkah }\end{array}$ \\
\hline & Edges & Tanaman & Sungai & Tanaman & $\begin{array}{l}\text { Pembatas } \\
\text { yang alami }\end{array}$ \\
\hline & Districts & Tidak ada & Tidak ada & Tidak ada & $\begin{array}{l}\text { Membuat } \\
\text { ruang dengan } \\
\text { karakter yang } \\
\text { berbeda agar } \\
\text { dapat dikenali } \\
\text { dan menarik } \\
\text { banyak } \\
\text { pengguna }\end{array}$ \\
\hline & Nodes & Gua Maria & Gua Maria & Gua Maria & Membuat \\
\hline
\end{tabular}

PAWON: Jurnal Arsitektur, Nomor 01 Volume VI, Januari - Juni Tahun 2022, ISSN 2597-7636 


\begin{tabular}{|c|c|c|c|c|c|}
\hline & & & & & $\begin{array}{l}\text { sehingga } \\
\text { orang datang } \\
\text { terus menerus }\end{array}$ \\
\hline & Landmark & Gereja & Gua Maria & Gua Maria & $\begin{array}{l}\text { Bisa menjadi } \\
\text { pusat } \\
\text { perhatian }\end{array}$ \\
\hline \multicolumn{2}{|c|}{ Fasilitas (Amenities) } & $\begin{array}{l}\text { Taman, jalur } \\
\text { pejalan kaki, } \\
\text { toilet,parkir, dan } \\
\text { tempat duduk }\end{array}$ & $\begin{array}{l}\text { Taman, jalur } \\
\text { pejalan kaki, } \\
\text { toilet,parkir, } \\
\text { dan tempat } \\
\text { duduk }\end{array}$ & $\begin{array}{l}\text { Taman, jalur } \\
\text { pejalan kaki, } \\
\text { toilet,parkir, dan } \\
\text { tempat duduk }\end{array}$ & $\begin{array}{l}\text { Taman, jalur } \\
\text { pejalan kaki, } \\
\text { toilet,parkir, } \\
\text { dan tempat } \\
\text { duduk }\end{array}$ \\
\hline \multirow[t]{3}{*}{$\begin{array}{c}\text { Pengg } \\
\text { unaan } \\
\text { di } \\
\text { waktu } \\
\text { yang } \\
\text { berbed } \\
\text { a } \\
\text { (Uses } \\
\text { at } \\
\text { Differe } \\
n t \\
\text { Times) }\end{array}$} & $\begin{array}{c}\text { Sepanjang } \\
\text { hari }\end{array}$ & $\begin{array}{l}\text { Ziarah, } \\
\text { berdevosi, } \\
\text { berdoa, } \\
\text { berkeliling dan } \\
\text { bersantai }\end{array}$ & $\begin{array}{l}\text { Ziarah, } \\
\text { berdevosi, } \\
\text { berdoa, } \\
\text { berkeliling dan } \\
\text { bersantai }\end{array}$ & $\begin{array}{l}\text { Ziarah, } \\
\text { berdevosi, } \\
\text { berdoa, } \\
\text { berkeliling dan } \\
\text { bersantai }\end{array}$ & $\begin{array}{l}\text { Tiga jenis } \\
\text { pengguna } \\
\text { ruang publik } \\
\text { yaitu, aktivitas } \\
\text { yang } \\
\text { diperlukan, } \\
\text { aktivitas } \\
\text { opsionalm } \\
\text { dan aktivitas } \\
\text { sosial }\end{array}$ \\
\hline & $\begin{array}{c}\text { Malam } \\
\text { hari }\end{array}$ & $\begin{array}{l}\text { Prosesi obor } \\
\text { Maria }\end{array}$ & $\begin{array}{l}\text { Trikatan Jumat } \\
\text { Legi }\end{array}$ & $\begin{array}{l}\text { Trikatan Jumat } \\
\text { Legi }\end{array}$ & $\begin{array}{l}\text { Seni cahaya } \\
\text { dapat } \\
\text { meningkatkan } \\
\text { penggunaan } \\
\text { dan vitalitas } \\
\text { ruang publik }\end{array}$ \\
\hline & Tahunan & Tahun Liturgi & Tahun Liturgi & Tahun Liturgi & $\begin{array}{l}\text { Merayakan } \\
\text { hari-hari } \\
\text { besar agama } \\
\text { Katolik }\end{array}$ \\
\hline
\end{tabular}

Sumber: Sumber Pribadi

\section{KESIMPULAN}

Terdapat tiga kasus yang digunakan untuk mengkaji sosiabilitas pola ruang di kawasan gua maria, yaitu kawasan gua Maria Lourdes Perancis, kawasan gua Maria Pohsarang dan kawasan gua Maria Sendangsono. Berdasarkan tinjauan ketiga kasus tersebut ditemukan lima strategi dalam menciptakan ruang publik yang bagus dan dipengaruhi beberapa detail variabel didalamnya. Dalam strategi atraksi dan destinasi (Attractions \& Destinations), suatu ruang memberi kesan pertama yang positif dan

PAWON: Jurnal Arsitektur, Nomor 01 Volume VI, Januari - Juni Tahun 2022, ISSN 2597-7636 
membuat kesan menarik. Dalam strategi identitas dan tampilan (Identity \& Image) yang dibagi lagi menjadi lima variabel yaitu paths dengan membentuk pola ruang yang berkesan disetiap langkah. Kedua Edges membuat pembatas yang alami. Ketiga, districts Membuat ruang dengan karakter yang berbeda agar dapat dikenali dan menarik banyak pengguna. Keempat nodes membuat berbagai tujuan atau aktivitas sehingga orang datang terus menerus. Kelima landmark merancang atau menempatkan sesuatu elemen simbolis bisa menjadi pusat perhatian di ruang tersebut. Dalam strategi fasilitas (Amenities) bisa berupa taman, jalur pejalan kaki, toilet,parkir, dan tempat duduk.

Penggunaan di waktu yang berbeda (Uses at Different Times) dibagi lagi menjadi tiga variabel berdasarkan penggunaan yaitu sepanjang hari diklasifikasi menjadi tiga jenis pengguna ruang publik yaitu, aktivitas yang diperlukan, aktivitas opsionalm dan aktivitas sosial. Penggunaan malam hari seni cahaya dapat meningkatkan penggunaan dan vitalitas ruang publik saat malam hari dan penggunaan tahunan dengan merayakan hari-hari besar agama Katolik. Secara keseluruhan, penelitian ini menjadi dasar yang dapat digunakan dalam membahas sosiabilitas pola ruang di Kawasan Gua Maria.

\section{DAFTAR PUSTAKA}

Kinney, A. 2013. Sacred Placemaking: A Design Response to the Changing Face of Religion in Canada (Unpublished master's thesis). University of Calgary, Calgary, $A B$

Chogle Shafeea. 2017. The Sacred and the everyday: Exploring the Relationship between Religious Space and Public. Space of Good Hope.

Hall, E. T. 1982. The Hidden Dimension, New York: Anchor Books, Doubleday

Victoria State Government. 2016. Urban Design Guidelines for Victoria. Victoria: State Government

Steven Terry. 2017. Build and they will come. Steven \& Associates

Hester, Randolph T. Planning Neighborhood Space with People, 2nd ed. New York, N.Y.: Van Nostrand Reinhold. 1984

PAWON: Jurnal Arsitektur, Nomor 01 Volume VI, Januari - Juni Tahun 2022, ISSN 2597-7636 
Dougherty, Dana. 2006. Embodying the city: Identity and use in urban public space. Virginia Polytechnic Institute and State University, Alexandria, Virginia

Zhuang Jia. 2008. Creating an Attractive Public Space for the Citizens. Sweden: Bleinge Institute of Technology

Lynch, Kevin. 1960. The Image of the City. Cambridge, Mass: Techology Press

Project for Public Spaces. 2007. What Is Placemaking?. Project for Public Spaces

Community Design Collaborative. 2019. Sacred Places Civic Spaces. At the intersection of Heritage, faith, and community

Community Planning Academy. 2017. Urban Design \& Placemaking. Charlotte Urban Design Center, 07, Juli 2017. Diambil dari: http://ww.charmeck.org/Planning/Land\%20Use\%20Planning/Communi tyPlanningAcademy/2017 07 Jul 12 UrbanDesign.pdf

Project for Public Spaces. Ten Strategies for transforming cities and public spaces through placemaking. Project for Public Spaces. 2014. https://www.pps.org/article/ten-strategies-for-transforming-citiesthrough-placemaking-public-spaces

Project for Public Spaces. Street as Places how transportaion can create a sense of community. Project for Public Spaces. 2014. https://www.pps.org/article/streets-as-places-how-transportation-cancreate-a-sense-of-community

PAWON: Jurnal Arsitektur, Nomor 01 Volume VI, Januari - Juni Tahun 2022, ISSN 2597-7636 